\title{
ANÁLISE DE NEOLOGISMOS POR EMPRÉSTIMO NO PORTUGUÊS BRASILEIRO
}

\author{
Mariane Antero Alves*
}

Resumo: Este artigo tem como objetivo analisar o processo de formação de palavras no português brasileiro através de empréstimos. Para tal fim, uma análise de dados linguísticos foi conduzida através da coleta e classificação de itens neológicos retirados de um jornal de grande circulação no Brasil e uma comparação foi realizada com os resultados obtidos pelo grupo de pesquisa neológica TermNeo, que também coletou dados com itens neológicos por empréstimo. O corpus para análise se constituiu de 496 itens, que foram classificados de acordo com o idioma de origem, a área temática e o subtipo de neologismo por empréstimo a que pertenciam, seguindo a classificação proposta pelo TermNeo. Os resultados foram analisados e, quando possível, comparados aos do TermNeo. Os resultados demonstraram que os estrangeirismos mais recorrentes são os de origem inglesa, reiterando os resultados do TermNeo, os relacionados à tecnologia e os da tipologia importação, sendo um reflexo do momento de profusão tecnológica que acontece nesta década.

Palavras-chave: Neologismo; estrangeirismo; português brasileiro.

Abstract: This article aims to analyze the process of word formation in Brazilian Portuguese through loanwords. In order to do so, an analysis of linguistic data was conducted by collecting and classifying neological items taken from a newspaper of general circulation in Brazil and a comparison was made with the results obtained by the neological research group TermNeo, which also collected data with neological items of loanwords. The corpus for

* Universidade Federal de Santa Catarina. 
analysis consisted of 496 items, which were classified according to the source language, thematic area and subtype of loanword neologism to which they belonged following the classification proposed by TermNeo. The results were analyzed and, if possible, compared to the ones of TermNeo. The results showed that the most frequent are the loanwords of English origin, confirming the results of TermNeo, the ones related to technology and the ones of the typology importation, being a reflection of the moment of technological profusion which happens in this decade.

Keywords: Loanword; lexical borrowing; Brazilian Portuguese.

\section{Introdução}

A língua é uma forma de expressão que permeia tarefas diárias, relações e interações entre os seres humanos e aquilo que os rodeia. Não é surpresa que os processos de evolução das línguas sejam influenciados pelos contextos espaço-temporais em que a humanidade se encontra e pelo seu estágio de evolução intelectual, científica e tecnológica.

Mais especificamente, se analisarmos o processo de formação e evolução das palavras do português brasileiro (doravante PB), veremos que, em meados do século XIX e início do século XX, a maior influência de estrangeirismos provinha da língua francesa, que, naquela época, era o maior "berçário" intelectual do mundo. Com o passar do tempo e as modificações no cenário econômico, científico e tecnológico, os EUA despontaram como uma grande potência mundial e a língua inglesa passou, então, a ser uma das mais influentes no mundo.

A globalização e o estreitamento das relações entre os países fizeram com que as línguas passassem também a estar em contato, através seja das pessoas seja das tecnologias de comunicação. Esse contato interlinguístico pode ser especialmente observado a partir da inserção de termos estrangeiros nas línguas, os chamados neologismos. Este é um dos processos mais recorrentes para formação de novas palavras e se dá através de empréstimo linguístico de uma 
língua A para uma língua $\mathrm{B}$, não constituindo um processo novo ou inusitado, pois vem ocorrendo na história das mais diversas línguas. Nas civilizações antigas, os processos de interferência entre as línguas aconteciam, por exemplo, quando dois povos se enfrentavam em guerras, fato que podia culminar na sobreposição de uma língua sobre a outra, com a absorção de certos termos na "língua resultante". Podemos observar esse tipo de contato nas línguas naturais que se desenvolveram a partir do latim, as chamadas línguas neolatinas, mas também em línguas de origem saxônica, como o inglês, que, devido ao contato, sofreu grande influência do latim no seu léxico. Na língua portuguesa, não foi diferente, pois ela sofreu influência de outras línguas, como o árabe, ${ }^{1}$ as línguas indígenas e as africanas.

No Brasil, a língua portuguesa foi imposta aos indíos que aqui viviam e, por isso, sofreu influências de várias línguas indígenas como, por exemplo, as da família tupi-guarani. Podemos ver essa influência em nomes ligados à natureza, como rios (Tietê; Tapajós; a própria palavra igarapé, que designa um pequeno rio, etc.), peixes (pirarucu, jundiá, tambaqui, etc.), alimentos (mandioca, açaí, guaraná, etc.), nomes de lugares, cidades e estados (Marajó, Jundiaí, Canguçu, Iguaçu), dentre muitos outros termos.

A grande diferença entre o que acontecia em épocas anteriores e hoje é a velocidade e a facilidade com que os processos se instalam. Com os meios de comunicação altamente desenvolvidos e disseminados pelos mais longínquos cantos do globo, o contato entre línguas que antes era muito improvável hoje acontece em uma fração de segundo.

Levando em consideração esse fenômeno, este estudo tem como objetivo discutir e analisar o processo de empréstimo linguístico atual no $\mathrm{PB}$, a partir de um corpus extraído de um jornal de grande

\footnotetext{
${ }^{1}$ Podemos observar a influência do árabe no PB através da introdução de palavras tais como açúcar, alfaiate e algodão, dentre muitas outras, quando da invasão da Península Ibérica pelos mouros, de acordo com Portugal (2011).
} 
circulação em território nacional. Os dados serão computados e posteriormente comparados aos resultados obtidos pelo grupo TermNeo: Observatório de Neologismos do Português Brasileiro Contemporâneo da Universidade de São Paulo, que também extraiu dados de jornais e revistas de grande circulação no Brasil. Os dados do TermNeo foram coletados entre os anos de 1993 e 2000, enquanto os nossos foram coletados no ano de 2011. Buscamos, assim, averiguar se existem diferenças entre os neologismos por empréstimos utilizados entre 1993-2000 e no período atual.

Neste trabalho faremos uma breve retomada do processo de neologismo por empréstimos na seção 2 , explicando como ele se caracteriza e os seus subtipos. Na seção 3, será delineada a metodologia aplicada para coleta e análise de dados. Os resultados serão analisados e discutidos na seção 4 e as conclusões apresentadas na seção 5 .

\section{Formação de novos vocábulos e tipologias neológicas}

Para nomear aquilo que é novo, seja no âmbito físico - como novas invenções ou tecnologias -, seja no âmbito das idéias emoções ou expressão-, o ser humano vem criando novas palavras ao longo de sua história. O termo neologia, do latim neo "novo" e do grego logos "estudo" significa "estudo do que é novo", e para a linguística é o "estudo de novas palavras" (CARVALHO, 1984).

Existe uma discussão acerca da necessidade do uso de palavras estrangeiras no $\mathrm{PB}$, especialmente quando elas são mantidas na sua forma original. Essa é uma questão bastante polêmica no Brasil, já que projetos de lei foram criados para tentar impedir o uso de palavras estrangeiras. ${ }^{2}$ Porém, o que podemos perceber é que há um volume imenso de inovações tecnológicas que nos bombardeiam seguidamente e, algumas vezes, uma língua não consegue acompanhar esse fluxo de criações/invenções que

\footnotetext{
${ }^{2}$ Projeto de lei no1676/99 (FARACO, 2001).
} 
precisam ser nomeadas. Geralmente, não há tempo de se criarem novos termos adaptados ou traduzidos e, por isso, os falantes acabam adotando o termo já em uso nos países em que essas tecnologias foram criadas ou estão sendo utilizadas. Contudo, isso não impede que, com o passar do tempo, o termo estrangeiro caia em desuso e um novo termo na língua materna seja utilizado. Foi o que aconteceu com muitos termos futebolísticos no PB, que primeiramente eram utilizados em inglês, como por exemplo, goalkeeper, que passou a ser arqueiro e mais atualmente goleiro; center-foward, ponteiro ou centro-avante e mais atualmente atacante, e o corner, que passou a ser conhecido como escanteio.

O neologismo, por sua vez, pode ser definido como o processo de criação de itens lexicais que não faziam parte do léxico de um determinado idioma. Segundo Alves (1984, p. 119), "o neologismo constitui uma unidade lexical de criação recente, uma nova acepção que se atribui a uma palavra já existente ou, então, a um termo recentemente emprestado a outro código linguístico". No $\mathrm{PB}$, as novas palavras podem ser criadas através de processos diferentes, como, por exemplo, neologismos fonológicos, sintáticos, semânticos, por truncação, por derivação regressiva, por empréstimo, dentre outros (ALVES, 1990). Como a presente pesquisa irá investigar somente o processo de neologismo por empréstimo, a seguir, daremos foco à definição e exemplificação dos subtipos dessa tipologia neológica.

\subsection{O neologismo por empréstimo: subtipos}

O processo de criação de uma nova palavra por empréstimo se dá pela incorporação de termos já existentes numa língua A por uma língua B. De acordo com Capuz (1997) e Alves (1984), o empréstimo pode acontecer de diferentes formas, criando "subtipos" dessa categoria de processo neológico.

Um desses subtipos de neologismo por empréstimo é a importação ou xenismo e ele acontece quando o vocábulo mantém a forma e significado do item, tal qual em sua língua de 
origem, como podemos perceber em palavras como marketing, internet, smartphone, sommelier, sushi, blog, dentre outras (CARVALHO, 1989; LEITÃO, 2006).

Outro tipo de neologismo por empréstimo é o loanblend ou híbrido, no qual há importação e substituição simultaneamente, sendo que o novo item já está agregado a uma classe morfológica da língua à qual ele passou a pertencer. Ele acontece pela "mistura" entre o item original e a substituição ou incorporação de termos da nova língua, sejam eles palavras ou apenas prefixos ou sufixos. No $\mathrm{PB}$, temos, como exemplo de híbridos, vocábulos como postar e tuitar. Esses dois vocábulos foram criados a partir dos itens lexicais de língua inglesa post e twitter (ambos substantivos na língua original), passando a se adjungir ao sufixo -ar, que os insere na categoria de verbo no PB.

O loanshift, substituição ou ainda decalque ocorre quando há a tradução literal do termo, como no caso de artificial intelligence, que passou no PB a inteligência artificial; broad band, como banda larga; e blogger, como blogueiro.

Biderman (1978) aponta ainda outro tipo de empréstimo, que acontece quando a forma estrangeira é adaptada à fonologia e à ortografia de uma língua, o que vamos chamar aqui de adaptação fonológica. É o caso no PB de shampoo (empréstimo do inglês), que se tornou xampu; mozzarella (do italiano), muçarela; abat-jour (do francês), abajur; e llama, (do espanhol), lbama.

Apesar de todos esses subtipos, não existe uma regra ou norma que vá determinar a tradução ou adaptação do termo, já que é possível encontrar ambos os termos em coocorrência no uso cotidiano.

\subsection{Os neologismos por empréstimo: aspectos morfossintáticos}

No que concerne aos aspectos morfossintáticos de neologismos por empréstimo, os novos itens lexicais incorporados ao português irão se incluir em categorias gramaticais, além de 
poder sofrer flexão de gênero e número e ainda se adjungir a prefixos e sufixos.

Em relação às classes gramaticais, os estrangeirismos são, na sua grande maioria, substantivos, mas também podem ser encontrados adjetivos e verbos (ALVES, 1984, 1990). Há uma tendência de se manter a classe a qual pertencem na língua de origem, mas pode também ocorrer a mudança da classe gramatical, como no caso de off-road, ${ }^{3}$ na frase: "O off-road mais vendido da categoria", que passa de adjetivo (na língua inglesa) para substantivo (no PB, no caso acima referido).

Ainda, segundo Alves (1984), os estrangeirismos podem também se flexionar em gênero, geralmente mantendo-o de acordo com a língua de origem. Quando este é considerado neutro no idioma-mãe, há uma preferência pela adoção, no $\mathrm{PB}$, do gênero masculino, como no caso de "o shopping". A flexão de número segue a mesma tendência do gênero ao manter a flexão como no original, mas também se podem utilizar as regras de flexão de número do próprio $\mathrm{PB}$.

Os neologismos por empréstimo podem se agregar a prefixos ou a sufixos pelo processo de derivação prefixal ou sufixal, da mesma forma que as palavras do PB. Podemos perceber esse fenômeno em palavras que se formaram por derivação prefixal, como anti-stress e mega-hair, ou por derivação sufixal, como em surfista, freudiano e roqueiro, que se anexaram aos sufixos do PB -ista, -ano e -eiro, respectivamente.

Por fim, podemos ainda observar a formação de neologismos por empréstimo através do processo de composição, como nos exemplos ticket alimentação, área vip e quilt livre.

\footnotetext{
${ }^{3}$ No inglês, a palavra off-road significa, de acordo com o dicionário Oxford (2005), aquilo que não é usado em vias públicas, como no exemplo: This is an off-road vehicle ("Esse é um veículo off-road").
} 


\section{Metodologia}

\subsection{Os dados da presente pesquisa}

Para a análise dos dados desta pesquisa sobre neologismos por empréstimo, foi montado um corpus com 1787 palavras coletadas manualmente a partir de várias colunas do jornal Folba de São Paulo. Esse jornal é uma publicação diária e foi escolhido por ser um dos periódicos de maior circulação em nível nacional.

As palavras coletadas foram classificadas de acordo com o idioma de origem, com a área temática e com o subtipo de estrangeirismo em que se encaixam.

Com relação ao idioma, os dados foram classificados de acordo com os seguintes idiomas: inglês, francês, espanbol, italiano e japonês e uma categoria denominada outros, que engloba os demais idiomas (alemão, árabe, coreano, etc.). Essa divisão foi feita a partir da coleta de dados, com a qual se pode verificar a quantidade de dados referentes a cada idioma.

A classificação segundo a área temática foi realizada de acordo com os seguintes temas: tecnologia/informática, música, esporte, culinária, economia, moda, arte, televisão, cultura, cinema e uma última divisão denominada outros. Essas classificações estão em conformidade com aquela proposta pelo grupo TermNeo, que será comentada na próxima subseção.

$\mathrm{Na}$ seção 2, foram abordados quatro subtipos de neologismo por empréstimo. A classificação dos dados coletados foi feita a partir desses subtipos, que são: importação, bíbrido, decalque e adaptaçãofonológica (AF).

Os dados foram computados e uma análise quantitativa foi realizada para se observar se haveria prevalência de um tipo de empréstimo sobre outros e também para se verificar a possível influência das línguas e áreas temáticas nas unidades linguísticas analisadas. Finalmente, os dados obtidos foram comparados com aqueles encontrados pelos pesquisadores do TermNeo. O Quadro 1 apresenta exemplos de classificação de vocábulos encontrados nos nossos dados, segundo as classificações anteriormente propostas. 


\section{QUADRO 1}

Exemplos de classificação dos dados encontrados na presente pesquisa

\begin{tabular}{|l|l|l|l|}
\hline Palavra & Idioma & Subtipo & Área temática \\
\hline blog & inglês & importação & tecnologia \\
\hline ferraristas & italiano & híbrido & esporte \\
\hline dogalemão & inglês & híbrido & outros \\
\hline rúgbi & inglês & adaptação fonológica (AF) & esporte \\
\hline zaatar & outros & importação & culinária \\
\hline
\end{tabular}

\subsection{Os dados do TermNeo}

O TermNeo ${ }^{4}$ é um grupo criado em 1988, na Universidade de São Paulo, e tem por objetivo a descrição da neologia no português através de análise de corpora, além de fazer sua descrição por áreas do conhecimento, o que possibilita a catalogação dessa nova terminologia e a elaboração de dicionários específicos para cada área catalogada (ALVES, 2006). Várias teses e dissertações foram publicadas com assuntos ligados à pesquisa realizada por seus participantes, bem como o desenvolvimento de dicionários, livros e artigos sobre neologia em áreas como Medicina, Economia, Dança, Ciências Agrárias, dentre outras.

Para formar sua base de dados, os pesquisadores iniciaram a coleta de unidades neológicas a partir de jornais e revistas de grande circulação no país, formando então o que denominam de BaseNeo. ${ }^{5}$ Estão disponíveis para consulta 13.472 dados coletados entre 1993 e 2000. Os dados referentes às análises quantitativas foram dispostos em gráficos, demonstrando a porcentagem de

\footnotetext{
${ }^{4}$ Alguns dados aqui informados foram retirados do site do projeto. Disponível em: < http://www.fflch.usp.br/dlcv/neo/index.php>. Acesso em: 18 jul. 2012 ${ }^{5}$ Base de Neologismos do Português Brasileiro Contemporâneo. Disponível em: <http://www.fflch.usp.br/dlcv/neo/consulta_baseneo.php >. Acesso em: 18 jul. 2012.
} 
ocorrência de neologismos ligados a alguns idiomas e a áreas específicas. Esses gráficos serão utilizados para uma comparação com os dados encontrados pela presente pesquisa.

Por fim, queremos ressaltar que todos os resultados obtidos serão computados a partir da sua frequência de ocorrência (em \%) para que se possa estabelecer uma comparação com os resultados obtidos pelo grupo TermNeo. Não foram aplicados testes estatísticos de significância aos resultados obtidos pela presente pesquisa.

\section{Análise dos dados coletados}

Através da coleta manual dos dados, obteve-se um total de 1.787 palavras (ou entradas) que formaram o banco de dados para a análise. Porém, nesse total, obtivemos ocorrências repetidas. Desconsiderando-se essas repetições, o banco de dados apresentou 496 entradas, chamadas aqui de "originais", que se caracterizam por serem neologismos por empréstimo. Dessa forma, a análise dos dados foi feita a partir dessas entradas originais, sendo cada novo termo computado uma única vez.

O banco de dados foi digitalizado para que a análise quantitativa pudesse ser feita com maior agilidade e para que os dados pudessem ser contabilizados apropriadamente. As entradas foram categorizadas de acordo com o idioma, a área temática, a tipologia (os quatro subtipos apresentados na seção 2). Cabe aqui ressaltar que, para as categorias idioma e área temática, serão apresentados primeiramente os resultados obtidos na presente pesquisa e, em seguida, os dados obtidos pelo grupo TermNeo. Para a categoria tipologia, serão apresentados somente os nossos resultados, já que não encontramos a análise por tipologias nos resultados do grupo TermNeo.

A partir do Gráfico 1, pode-se observar que a língua inglesa obteve destaque nos resultados, representando $73 \%$ dos dados coletados, sendo seguida pelo francês com $8 \%$, italiano e espanhol 
com 5\%, e japonês com 1\%. Os dados representando outros idiomas como árabe, alemão, chinês abrangeram $8 \%$ dos dados.

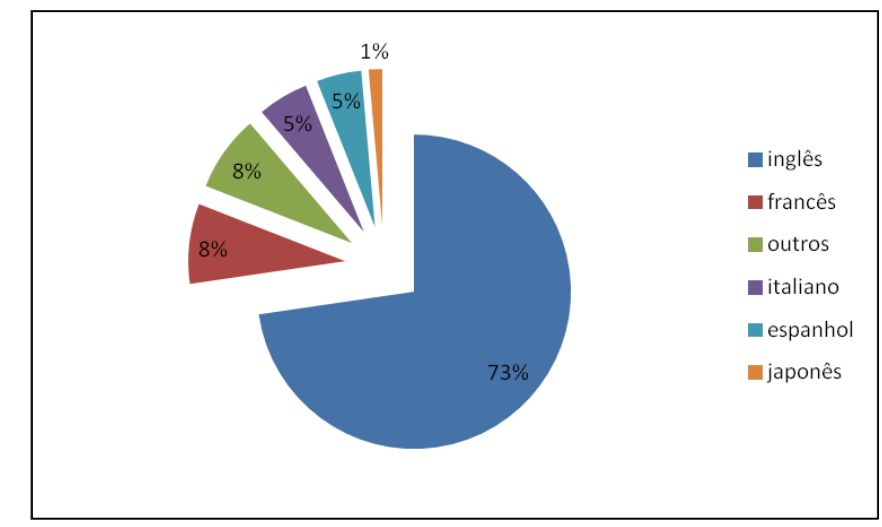

GRÁFICO 1: Porcentagem de neologismos por empréstimo de acordo com o idioma extraídos do nosso banco de dados

Esse resultado já era esperado, uma vez que, nos dias atuais, as maiores "incubadoras" de criação e inovação tecnológica no mundo se concentram em número expressivo nos EUA. Não é de estranhar que os novos produtos sejam nomeados e se espalhem pelo mundo de acordo com a língua falada nos países que os produziram. Por essa razão, nomes de empresas e de linhas de produtos como Apple, Google, Microsoft e outros são tão comuns para os falantes do PB. Podemos observar também certa tendência das empresas (mesmo aquelas em que o inglês não é o idioma do país em que estão sediadas) em nomear seus produtos com termos em inglês, dado o fato de ser esse idioma um dos mais falados e disseminados mundialmente, sendo até mesmo considerado como língua franca (SEIDLHOFER, 2004). Os dados apresentados anteriormente no Gráfico 1 ajudam a corroborar a prevalência de termos em inglês em termos neológicos do PB. Esse resultado reitera os dados encontrados pelo grupo TermNeo, como pode ser visto no Gráfico 2 . 


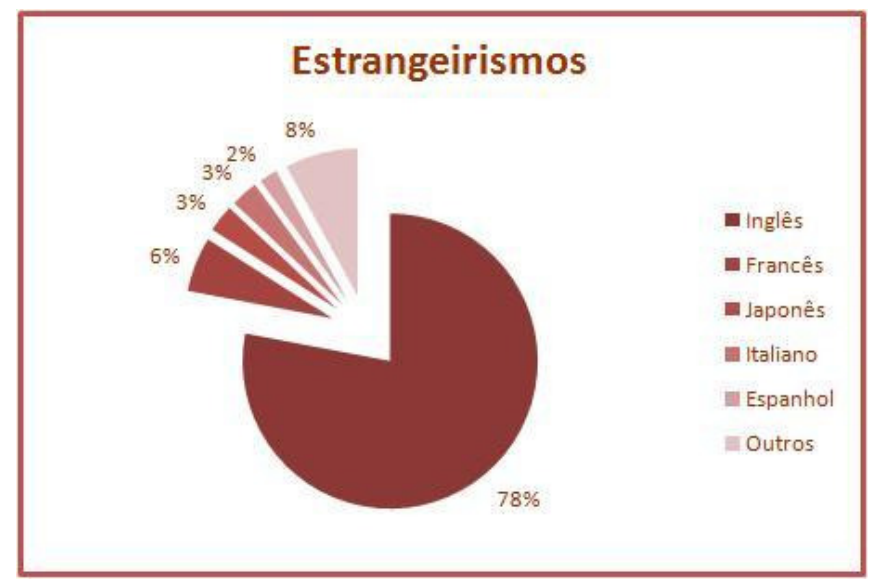

GRÁFICO 2: Porcentagem de neologismos por empréstimo de acordo com o idiomaextraídos dos resultados do grupo TermNeo ${ }^{6}$

Uma análise comparativa entre os dois gráficos revela certa similaridade entre a distribuição dos neologismos por empréstimo no PB. Com relação à língua inglesa, houve uma variação de $5 \%$ entre as duas pesquisas. $O$ francês se manteve como a língua que ocupa o segundo lugar nesse ranking e houve uma alteração na ordem entre japonês, italiano e espanhol entre os dados da presente pesquisa e a realizada pelo grupo TermNeo. Na pesquisa do TermNeo, o japonês e o italiano estavam no terceiro lugar com $3 \%$ dos itens, seguidos pelo espanhol (2\%). Já, para a presente pesquisa, observa-se que italiano e espanhol apresentaram 5\% das entradas, enquanto o japonês apresentou apenas $1 \%$. Outros idiomas representaram $8 \%$ em ambas as pesquisas.

Analisando os dados oriundos da língua inglesa de acordo com a área temática, observa-se, através do Gráfico 3, que os dados referentes à area "tecnologia/informática" foram aqueles que prevaleceram, com $40 \%$ dos dados, seguidos de "esporte" com 12\%, "economia" com 7\%, música com 6\%, "televisão" com 4\%, "culinária”

\footnotetext{
${ }^{6}$ Os gráficos 2, 4 e 6 aqui apresentados são referentes aos resultados obtidos pelo grupo TermNeo. Disponíveis em: <http://www.fflch.usp.br/dlcv/neo/ dados_termneo.php>. Acesso em: 18 jul. 2012.
} 
e "cinema" com 3\%, "moda" com 2\%, "arte" e "cultura" com 1\%. Os dados que representavam outras áreas abrangeram 21\% dos dados.

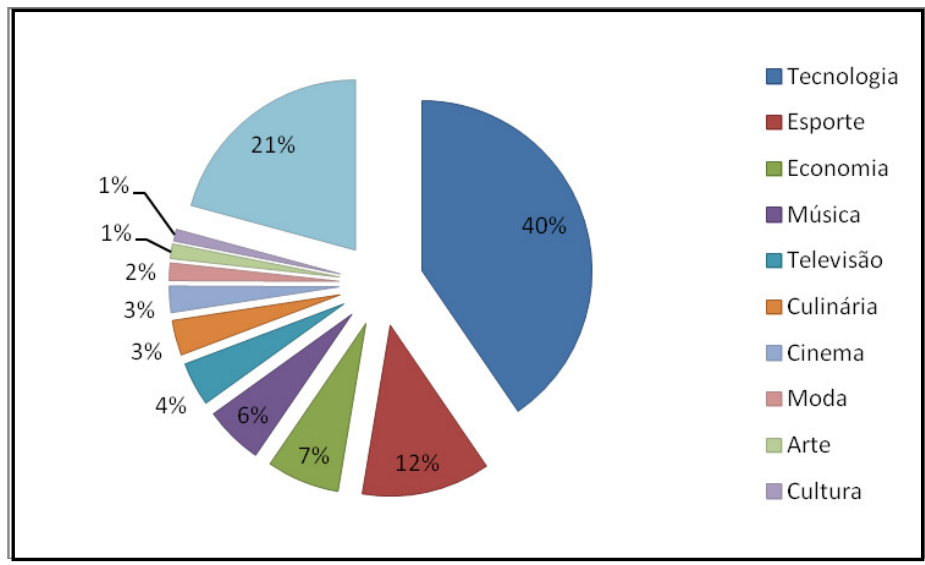

GRÁFICO 3: Porcentagem de neologismos por empréstimo da língua inglesa, categorizados de acordo com a área temática, extraídos do nosso banco de dados

No Gráfico 4, podemos observar a distribuição dos dados de língua inglesa do grupo TermNeo, de acordo com a área.

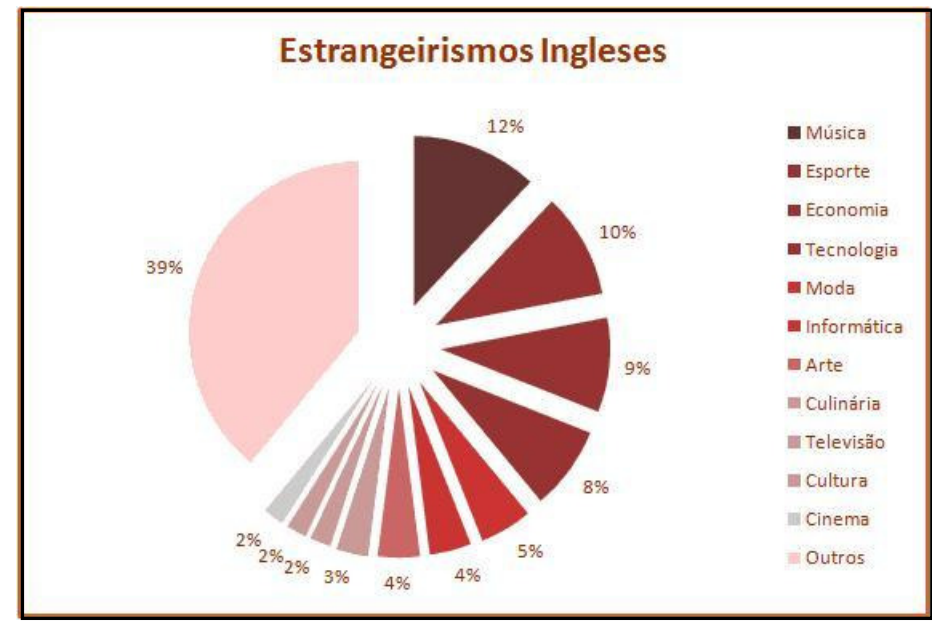

GRÁFICO 4: Porcentagem de neologismos por empréstimo da língua inglesa, de acordo com a área temática, extraídos dos resultados do grupo TermNeo 


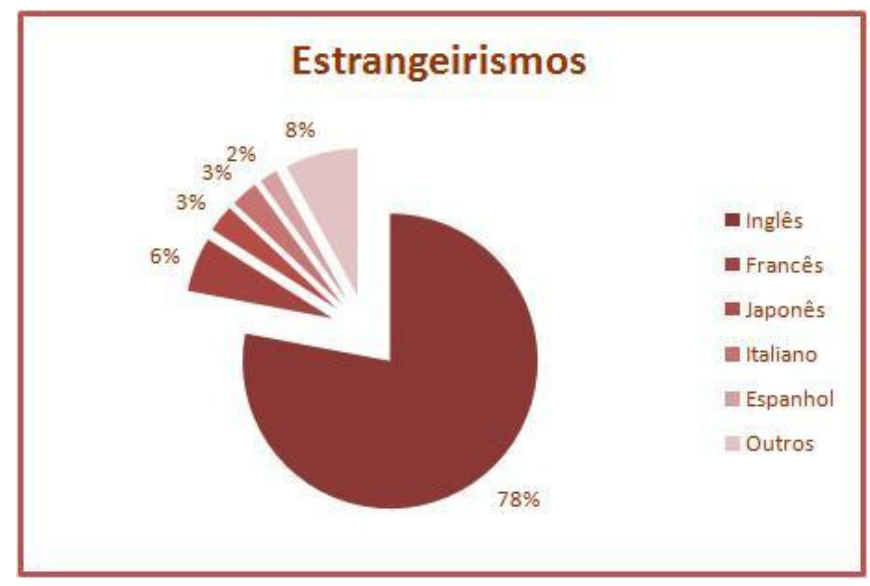

GRÁFICO 2: Porcentagem de neologismos por empréstimo de acordo com o idiomaextraídos dos resultados do grupo TermNeo ${ }^{6}$

Uma análise comparativa entre os dois gráficos revela certa similaridade entre a distribuição dos neologismos por empréstimo no PB. Com relação à língua inglesa, houve uma variação de $5 \%$ entre as duas pesquisas. $O$ francês se manteve como a língua que ocupa o segundo lugar nesse ranking e houve uma alteração na ordem entre japonês, italiano e espanhol entre os dados da presente pesquisa e a realizada pelo grupo TermNeo. Na pesquisa do TermNeo, o japonês e o italiano estavam no terceiro lugar com $3 \%$ dos itens, seguidos pelo espanhol (2\%). Já, para a presente pesquisa, observa-se que italiano e espanhol apresentaram 5\% das entradas, enquanto o japonês apresentou apenas $1 \%$. Outros idiomas representaram $8 \%$ em ambas as pesquisas.

Analisando os dados oriundos da língua inglesa de acordo com a área temática, observa-se, através do Gráfico 3, que os dados referentes à area "tecnologia/informática" foram aqueles que prevaleceram, com $40 \%$ dos dados, seguidos de "esporte" com 12\%, "economia" com 7\%, música com 6\%, "televisão" com 4\%, "culinária”

\footnotetext{
${ }^{6}$ Os gráficos 2, 4 e 6 aqui apresentados são referentes aos resultados obtidos pelo grupo TermNeo. Disponíveis em: <http://www.fflch.usp.br/dlcv/neo/ dados_termneo.php>. Acesso em: 18 jul. 2012.
} 
Ao se compararem os dados obtidos na presente pesquisa (Gráfico 3) com os dados obtidos pelo grupo TermNeo (Gráfico 4), percebe-se certa diferença. Dentre os dados encontrados para empréstimos da língua inglesa em nossos dados, $40 \%$ estão relacionados à área de tecnologia/informática. Já, nos dados da pesquisa do grupo TermNeo, se somadas as áreas de tecnologia (8\%) e informática (4\%), ambas abrangem $12 \%$ dos termos. Cabe ressaltar, porém, que, se somados os valores de tecnologia e informática na pesquisa do TermNeo, essa se igualaria à área temática de música (12\%), que ocupa o primeiro lugar em porcentagem dentre todas as áreas temáticas da pesquisa realizada pelo grupo. Em nossos dados, no entanto, a área de música ocupa apenas a quarta posição, considerando que a área de informática foi agregada à de tecnologia.

Uma possível explicação para a diferença entre os resultados obtidos pelas duas pesquisas pode ser o fato de que os dados do grupo TermNeo foram coletados entre os anos de 1993 e 2000 e os nossos no ano de 2011 . Levando-se em conta que a grande disseminação de artefatos tecnológicos se deu a partir da presente década, torna-se evidente o fato de que poderia haver um salto entre os resultados obtidos na década passada e nesta, já que o uso linguístico está muito relacionado não só com questões linguísticas propriamente ditas, mas com questões sociohistóricas que vão demonstrar certas tendências rumo à mudança e evolução nas línguas (LABOV, 2008).

A mesma análise foi feita para os estrangeirismos de língua francesa. Para podermos estabelecer uma comparação com os resultados do grupo TermNeo, os nossos dados foram categorizados em culinária, moda, sociedade, arte, bebidas, animais e outros, de acordo com a categorização realizada pelo grupo. Os resultados obtidos para esta pesquisa são apresentados no Gráfico 5. 


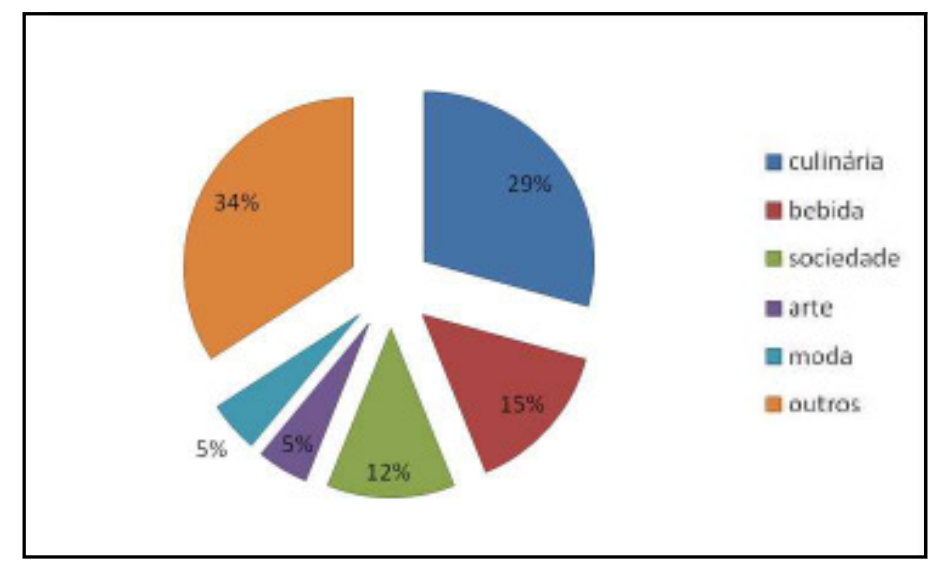

GRÁFICO 5: Porcentagem de neologismos por empréstimo da língua francesa, categorizados de acordo com a área temática, extraídos do nosso banco de dados

Houve prevalência, para os dados de língua francesa encontrados na presente pesquisa, da área de culinária, com $29 \%$ dos dados, seguida pela área de bebida com 15\%, sociedade com $12 \%$, e arte e moda com $5 \%$ cada. Os dados relativos a animais não apresentaram nenhuma entrada e outras áreas totalizaram 34\%.

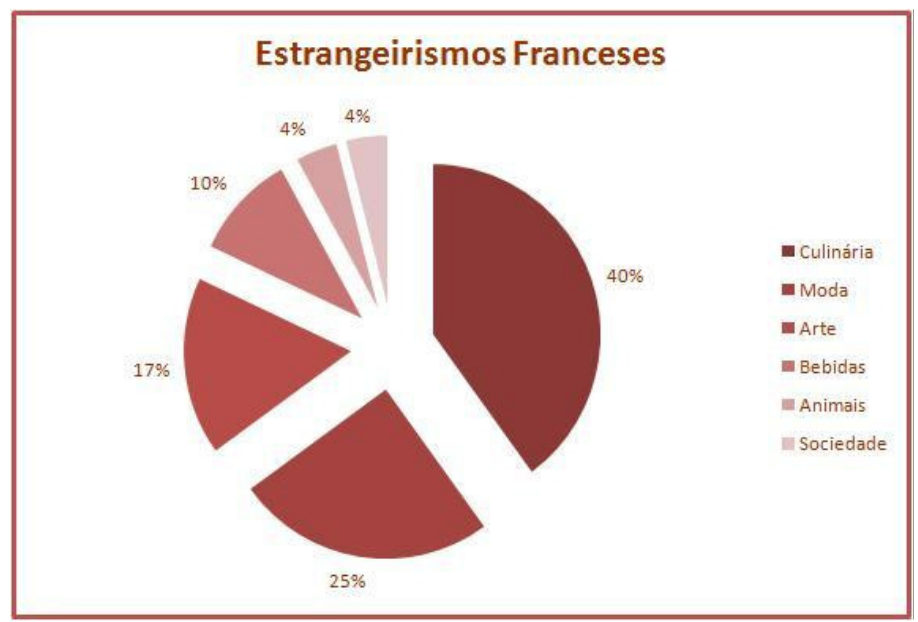

GRÁFICO 6: Porcentagem de neologismos por empréstimo da língua inglesa, de acordo com a área temática, extraídos dos resultados do grupo TermNeo 
Na comparação com os dados do grupo TermNeo, apresentados no Gráfico 6, observa-se uma inversão na ordem de ocorrências a partir do item que ocupou segundo lugar, pois "culinária" ocupou o primeiro lugar em ambas as pesquisas.

Podemos observar de acordo com os Gráficos 5 e 6 que os neologismos por empréstimos relacionados a culinária são os que predominam no $\mathrm{PB}, \mathrm{com} 29 \%$ para os dados da presente pesquisa e $40 \%$ para os dados do grupo TermNeo. Houve também diferença entre os dados relacionados a sociedade, com $12 \%$ na presente pesquisa contra $4 \%$ na do grupo TermNeo, arte com 5\% nos nossos dados e $25 \%$ nos do TermNeo, e animais, que não apresentou nenhuma ocorrência nos dados na presente pesquisa e obteve $4 \%$ na pesquisa do grupo TermNeo.

Em relação à análise por área temática - levando-se em conta a totalidade dos dados obtidos, independentemente do idioma - pode-se observar, através do Gráfico 7 , que a categoria que mais se destacou foi a da "tecnologia" com $33 \%$ dos dados, corroborando o fato de que essa parece ser a área que mais contribui com o dinamismo na criação de novas unidades lexicais por empréstimo. Ela foi seguida pela área de "esportes", com 12\%; "culinária", com 11\%; "economia", com 6\%; "música", com $4 \%$; "televisão", com 3\%; "arte", "cinema" e "cultura", com $2 \%$; e "moda", com $1 \%$. Outros itens que não se enquadraram nas categorias acima somaram $24 \%$ dos dados (categoria "outros)". 


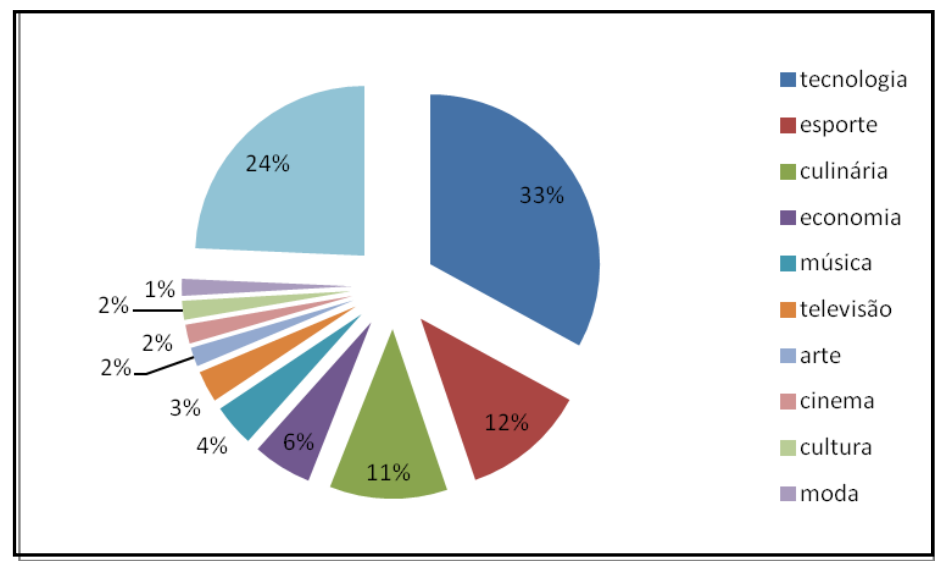

GRÁFICO 7: Porcentagem de neologismos por empréstimo de acordo com a área temática, extraídos do nosso banco de dados.

O Quadro 2 apresenta exemplos de dados retirados do nosso banco de dados, relacionados a cada área temática.

\section{QUADRO 2}

Exemplos extraídos do banco de dados, de acordo com a área temática

\begin{tabular}{|l|l|l|l|l|l|l|l|l|}
\hline Tecnologia & Esporte & Culinária & Economia & Música & Televisão & Arte & Cinema & Moda \\
\hline smartphone & doping & bacon & marketing & rap & talk show & pop-arte & set & jeans \\
tablet & críquete & bambúnguer & IPO & country & gameshow & brodway & road & biquíni \\
Google & cross-country & brûllée & bolding & folk & realityshow & cult & movie & outlet \\
Apple & rúgbi & croquete & trading & roqueiros & pay-per-view & teatrod'art & stunt \\
fashionista \\
\end{tabular}

No que tange os subtipos de neologismo por empréstimos, a análise de dados apontou que $80 \%$ dos nossos dados se enquadram na categoria importação, seguido por adaptação fonológica (AF), com 10\%, por bíbridos, com $7 \%$ e por decalque com 3\%, conforme ilustrado pelo Gráfico 8.

\footnotetext{
${ }^{7}$ A sigla IPO, Initial Public Offering, corresponde às primeiras ações de uma empresa que são colocadas à venda no mercado de ações.
} 


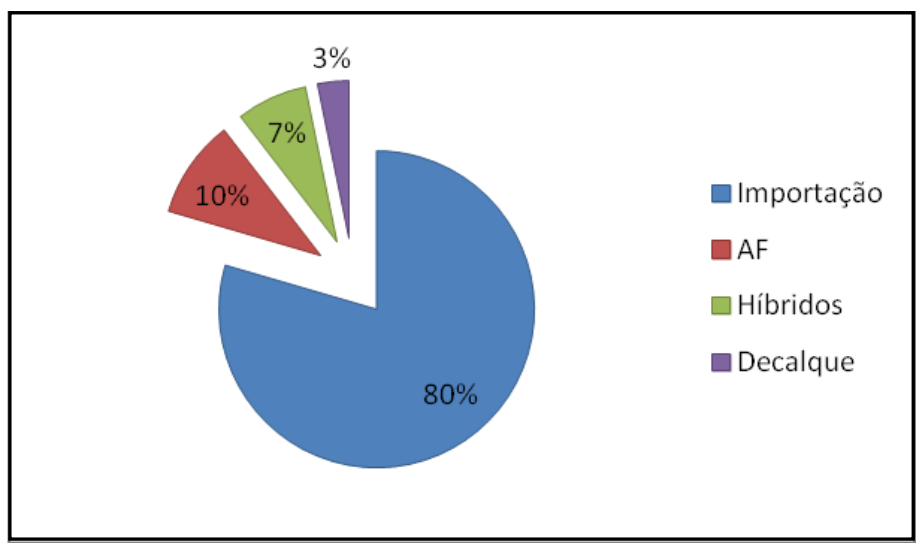

GRÁFICO 8: Porcentagem de neologismos por empréstimo de acordo com a tipologia, extraídos do nosso banco de dados

Uma das possíveis razões para a prevalência desse subtipo pode ser atribuída ao fato de que o léxico, principalmente aquele relativo à tecnologia, está em constante e rápida mudança, fazendo com que novos termos sejam lançados quase que diariamente. Diante da profusão de novos termos, parece não haver tempo suficiente para a criação de termos na própria língua incorporadora para denominar os termos estrangeiros que aparecem, dado que em um dia eles podem estar sendo utilizados em peso pelos falantes e, no outro, eles já estão obsoletos (como foi o caso de palavras como disquete e palmtop, por exemplo, que praticamente deixaram de ser utilizadas).

\section{Conclusões}

A análise de dados aqui conduzida mostrou que, dos dados sobre neologismos coletados pela presente pesquisa, a maior parte deles têm como língua original o inglês, são, na maioria, relacionados à área de tecnologia/informática e, dentre os quatro subtipos de neologismos por empréstimo, a maior parte dos dados constistiu de importação.

Podemos observar, a partir desses resultados, que a influência americana, sentida no Brasil nos âmbitos econômico, 
cultural, intelectual, científico e tecnológico, é refletida também no âmbito linguístico através dos empréstimos, já que os EUA se configuram ainda hoje como uma grande potência mundial e também como um dos grandes criadores de empresas que lançam no mercado econômico uma expressiva quantidade de itens relacionados principalmente, à tecnologia.

Um dado interessante se revelou na comparação com os dados do grupo TermNeo, que foram coletados uma década antes da presente pesquisa. Esses dados não apresentaram resultados tão expressivos em favor da área de tecnologia, uma vez que, como explicado anteriormente, a grande disseminação de tecnologias aconteceu, de forma contundente, a partir do início dessa década. Podemos ainda observar que essa profusão de itens tecnológicos teve reflexo sobre a nossa língua, já que o subtipo importação foi aquele que mais se destacou. No atual cenário, vemos constantemente o lançamento de um novo aparelho ou software que rapidamente é absorvido pelo mercado e que o nome que lhe é dado originalmente acaba também sendo absorvido na sua forma integral ou com algumas adaptações fonológicas (subtipo que ficou em segundo lugar na nossa análise).

Cabe também ressaltar que, nas análises comparativas entre os nossos dados e aqueles coletados pelo grupo TermNeo, nem sempre houve similaridade entre os resultados. Podemos atribuir tal fato à diferença no número de dados analisados pelas duas pesquisas, sendo que, para nossa pesquisa, obtivemos 496 itens lexicais, enquanto o grupo TermNeo analisou 13.472 entradas.

Por fim, podemos concluir que, sendo a língua uma das habilidades humanas na interação com o mundo, esta, indubitavelmente, será influenciada e refletirá a realidade humana que a permeia. Portanto, a língua não pode ser considerada como algo estagnado, que não se modifica ao longo do tempo e do espaço. Pelo contrário, ela se modifica, varia e se altera para atender a uma das mais primordiais necessidades do ser humano: a necessidade de se expressar. 


\section{Referências}

ALVES, I. M. A integração de neologismos por empréstimo ao léxico do português. Alfa, São Paulo, v. 28, p. 119-126, 1984.

ALVES, I. M. Neologismo: criação lexical. São Paulo: Ática, 1990.

ALVES, I. M. A observação sistemática da neologia lexical: subsídios para o estudo do léxico. Alfa, São Paulo, v. 50, p. 131-144, 2006.

BIDERMAN, M. T. C. Teoria lingüística: lingüística quantitativa e computacional. Rio de Janeiro: Livros Técnicos e Científicos, 1978.

CAPUZ, J. G. Towards a tipological classification of linguistic borrowings. Revista Alicantina de Estudos Ingleses, Alicante, v.10, p. 81-94, 1997.

CARVALHO, N. O que é neologismo. São Paulo: Brasiliense, 1984.

CARVALHO, N. Empréstimos linguísticos. São Paulo: Ática, 1989.

FARACO, C. A. Estrangeirismos: guerras em torno da língua. São Paulo: Parábola, 2001.

LABOV, W. Padrões sociolinguísticos. São Paulo: Parábola Editorial, 2008.

LEITÃO, I. C. Angliscismos no português do Brasil: um estudo lexicográfico Aurélio-Houaiss. 2006. Dissertação (Mestrado em Letras Lingüística e Língua Portuguesa) - Araraquara, Universidade Estadual Paulista Júlio de Mesquita Filho.

OXFORD Advanced Learners's Dictionary of Current English. 7. ed. Oxford: Oxford University Press, 2005.

PORTUGAL, A. R. M. da C. M. O legado árabe no Brasil. Ibérica: Revista Interdisciplinar de Estudos Ibéricos e Ibero-americanos, Juiz de Fora, v. V, n.16, p. 4-21, 2011.

SEIDLHOFER, B. Research perspectives on teaching English as a lingua franca. Annual Review of Applied Linguistics, Cambridge, v. 24, p. 209-239, 2004.

TERMNEO. Observatório de neologismos do português contemporâneo. São Paulo, jul. 2011. Disponível em: < http://www.fflch.usp.br/dlcv/neo/ index.php>. Acesso em: 22 jul. 2011.

Recebido para publicação em 21 de agosto de 2012 Aprovado em 5 de novembro de 2012 